\title{
A importância da fotografia no ensino do francês em Moçambique
}

\section{The importance of photography in teaching french in Mozambique}

\begin{abstract}
Alexandre António Timbane*
RESUMO: Moçambique tem uma diversidade linguística complexa. O português é a língua oficial e concorre com mais de vinte línguas do grupo bantu distribuídas de forma desigual pelo país. $O$ francês tem o estatuto de língua estrangeira e é aprendido a partir da $9^{a}$ até $12^{a}$ classes do ensino secundário. A presente pesquisa versa sobre a complexidade do ensino do francês usando a fotografia (documento autêntico) nas escolas secundárias públicas e privadas de Moçambique e pretende: discutir metodologias de ensino da língua estrangeira; analisar o manual escolar Le nouve/ espaces-1 e, finalmente, sugerir caminhos para explorar a fotografia em prol da aquisição das competências comunicativas em francês. Baseando-se na abordagem comunicativa, a pesquisa procura mostrar que a fotografia é um potencial material de aprendizagem de uma língua possibilitando a criação de atividades de expressão e comunicação oral e escrita. Com pesquisa com manual concluiu-se que as fotografias são pouco exploradas nas aulas de francês e que seria interessante que os professores aproveitassem este material para o desenvolvimento de várias atividades para que 0 aluno progrida desenvolvendo as quatro competências.
\end{abstract}

PALAVRAS-CHAVE: Ensino. Fotografia. Língua francesa. Abordagem comunicativa.

ABSTRACT: Mozambique has a complex linguistic diversity. The portuguese is the official language and competes with over twenty bantu languages spread throughout on the country. The french language has the status of foreign language and it's learned from 9th to 12th grades of secondary education. This research deals with the complexity of teaching the french language using the photo (authentic document) in public and private secondary schools in Mozambique and discusses methodologies of foreign language teaching; to analyze the textbook Le Nouvel Espaces-1 and finally, suggest how can we explore the photo in favor of the acquisition of communication skills in french. Based on the communicative approach, the research attempts to show that the photo is a potential material for learning of the language and it can help to create activities for oral and written expression and communication. With the manual

\footnotetext{
* Doutor em Linguística e Língua Portuguesa, Mestre em Linguística e Literatura. Professor no Instituto Superior de Gestão e Empreendedorismo Gwaza Muthini (Moçambique) e Professor na Academia de Ciências Policiais (Moçambique). Docente de Língua Francesa, Linguística Forense e Técnicas de Expressão e de Comunicação. E-mail: alextimbana@gmail.com.
} 
survey we concluded that the photos is not well explored in french classes and it would be interesting that the teachers enjoy this material for the development of various activities for the student to progress developing the four skills.

KEYWORDS: Teaching. Photography. French language. Communicative approach.

\section{Considerações iniciais}

Moçambique é um país lusófono que se caracteriza por uma diversidade linguística. É um país com pouco mais de 24 milhões de habitantes e com vinte línguas bantu espalhadas pelo país. Segundo Ngunga e Bavo (2011, p.14-15), as quatro línguas mais dominantes no país são: emakhuwa (26.1\%), português $(10.8 \%)$, xichangana $(10.5 \%)$ e cisena $(7.8 \%)$.

A língua portuguesa é de prestígio por ser oficial e amparada pela Constituição da República de Moçambique (2004), instrumento que dá pouca relevância às línguas bantu moçambicanas faladas pela maioria da população. A maior parte da população habita nas zonas rurais e fala as diversas línguas bantu. Para além destas línguas africanas, Moçambique conta com cinco línguas de asiáticas (gujarate, memane, hindu, urdo e o árabe) faladas por comunidades asiáticas radicadas no país e pela comunidade islã enraizada principalmente na região norte de Moçambique (TIMBANE, 2013).

O importante a ser sublinhado é que a educação é feita exclusivamente em português em paralelo com algumas línguas europeias como línguas estrangeiras, nomeadamente 0 francês e 0 inglês. As línguas bantu moçambicanas, embora sendo as mais faladas do país, não têm nenhum espaço legal, segundo a política linguística e o planejamento. $O$ que se verifica em Moçambique é que há um crescimento acelerado de falantes de português, resultado de políticas governamentais que incentivam a educação massiva e gratuita no ensino primário, fato que reduz os índices de analfabetismo principalmente nas zonas urbanas e suburbanas. Os ensinos médio e superior não são gratuitos, o que significa que cada moçambicano deve custear com 
recursos próprios o ensino dos seus filhos. O ensino em Moçambique é dividido em três níveis principais:

a) Nível primário: que corresponde de $1^{\mathrm{a}}$ a $7^{\mathrm{a}}$ classe;

b) Nível secundário: que corresponde de $8^{\mathrm{a}}$ a $12^{\mathrm{a}}$ classe e

c) Nível superior: que corresponde aos quatro anos para obtenção do grau de licenciado, dois anos para mestrado e dois para o doutorado.

No ensino secundário, há saídas profissionalizantes - os alunos que desejarem se profissionalizar podem seguir os cursos técnicos: comerciais, industriais, formação de professores, enfermagem, entre outros. A língua estrangeira mais privilegiada em todos os níveis é a inglesa, pois ela é ensinada desde a $6^{a}$ classe do ensino primário de forma obrigatória. A língua francesa também tem o estatuto de língua estrangeira e sua oferta como disciplina obrigatória inicia-se no $9^{\circ}$ ano, desde 2006 , opcional na $11^{\mathrm{a}}$ e $12^{\mathrm{a}}$ classes desde 1994.

A Língua Francesa é a segunda língua estrangeira a ser incorporada no ensino, como uma das ferramentas necessárias para a participação efectiva do aluno na vida social e política do país. É uma disciplina opcional neste ciclo e é introduzida a partir da $9^{a}$ classe com objectivo de levar os alunos a comunicar, oralmente e por escrito, num nível básico, na Língua Francesa em diferentes situações de comunicação. A introdução desta disciplina neste ciclo deverá ser gradual tendo em conta a disponibilidade de professores e poderá obedecer a um regime específico sob a forma de módulos intensivos ou níveis, de acordo com o contexto. (MINED, 2007, p.40)

O ensino do francês em Moçambique é garantido por professores moçambicanos formados na Universidade Pedagógica, instituição de ensino superior com delegações em várias cidades do país. O francês, segundo o Ministério da Educação de Moçambique (1994, p.2) tem os seguintes objetivos:

(a) Providenciar o acesso ao saber, ao conhecimento técnicocientífico, à cultura e literaturas universais e contemporâneos;

(b) Facilitar os estudos dos alunos do ensino superior, sabendo que as várias disciplinas recorrem a bibliografia nessa língua;

(c) Contribuir para uma melhor comunicação e um intercâmbio com o exterior, em particular com os países francófonos. 
Moçambique não faz fronteira com nenhum país francófono, mas pensa na integração continental porque em África existem vinte países (ex-colônias da França) que adotaram o francês como língua oficial e quatro países que entraram na francofonia por razões político-econômicas. Em todos esses países, o francês é segunda língua para a maioria da população. Dessa forma, a presente pesquisa faz uma reflexão metodológica e prática sobre o uso da fotografia no ensino de francês como língua estrangeira.

Como problema, questiona-se a metodologia usada pelos professores em sala de aula. Avança-se às hipóteses seguintes: a foto não tem sido valorizada em sala de aula nas seis escolas pesquisadas; a foto não ajuda, nem serve de meio de aprendizagem no ensino de francês; os professores do ensino básico conhecem a metodologia do trabalho com a foto mas, não têm tempo; as turmas numerosas não permitem um trabalho mais profundo. A fotografia está presente de forma expressiva nos manuais escolares e deve ser explorada de forma exaustiva para se desenvolverem atividades que levem o aluno ao desenvolvimento de competências comunicativas. $O$ trabalho tem como objetivos: (a) discutir metodologia de ensino; (b) analisar o manual escolar Le nouvel espaces-1 e (c) propor formas de uso nas aulas de francês.

Na primeira parte, discute-se os conceitos de aprendizagem olhando-se para os tipos de aprendizagem porque cada aluno tem a sua forma de aprender. O professor, ao variar as atividades na aula de língua, procura satisfazer as necessidades dos alunos. Na segunda parte, abordam-se os documentos autênticos que são indispensáveis para o professor que não quer se limitar ao manual disponibilizado pelo Ministério da Educação. Passa-se em revista os tipos de documentos autênticos bem como os tipos de imagem. A imagem fixa é o objeto principal da presente pesquisa observando como isso se manifesta no manual escolar Le nouvel espaces-1. O artigo termina apresentando os resultados de uma análise do manual e propostas para um trabalho mais proveitoso com a fotografia. Comecemos agora com a noção aprendizagem. 


\section{Noção de aprendizagem}

O conceito de aprendizagem pode trazer conceitos diferentes dependendo da área de estudo. Para Legendre (1993), a aprendizagem se define como o conjunto de atividades colocadas à disposição do sujeito e que são suscetíveis de despertar processos internos com vista ao alcance dos objetivos. Champy e Eteve (1994) definem aprendizagem como a aquisição de uma nova conduta, a capacidade de praticar um comportamento novo ou uma maneira de estar e de ser.

O dicionário Le petit Robert define aprendizagem como sendo "o fato de aprender uma profissão manual ou técnica na escola ou num lugar particular"1 (REY, 1998, p.61, tradução nossa). As definições aqui apresentadas têm aspetos em comum: a aprendizagem vista como tomada de conhecimento de determinado saber adquirido formal ou informalmente. Na didática de línguas, entende-se por aprendizagem a ação que consiste na aquisição de uma língua para que seja utilizada em determinada situação da vida social.

A escola é o espaço formal onde, por meio de professores ou ainda de especialistas dotados de conhecimentos metodológicos e práticos, planejam-se e executam o processo de ensino e aprendizagem. Este processo é consciente, organizado, tem objetivos e metodologias próprias que fazem com que o aluno adquira competências ou conhecimentos diversos. Neste caso, em que se fala de aprendizagem de uma língua, adquiri-se competências de expressão e de comunicação oral e escrita. Neste cenário (do processo de ensinoaprendizagem), entram em jogo três atores fundamentais: o professor, os conteúdos e o aluno (o principal).

Mas é importante sublinhar que a palavra aluno (eleve, em francês) está conotada de sentido negativo, pois, na metodologia tradicionalista, partia-se do pressuposto de que o "aluno é uma tábua rasa" que chega à escola sem nenhum conhecimento. O empirismo, segundo Gomes (2011), define o cérebro como uma tábua rasa, vazia, desestruturada no que diz respeito aos fatos

\footnotetext{
${ }^{1}$ Le fait d'apprendre un metier Manuel ou technique dans une école ou chez un particulier.
} 
mentais, ou seja, é como se o aluno fosse um tambor que chega vazio, sem nada e que alguém (o professor, neste caso) precisa encher de alguma coisa (de conhecimento).

Mas essa teoria não é verdadeira, porque o "cérebro é programado para analisar a experiência e construir saberes a partir dela (...) o cérebro humano pode gerar uma infinidade de sentenças através de regras." (GOMES, 2011, p.25). Estes conhecimentos aprendidos na sociedade podem ser sistematizados e organizados em prol da aprendizagem em sala de aula. 0 importante é que o professor precisa conhecer essas potencialidades para poder aproveitá-la. Por isso, neste trabalho, adotaremos a palavra francesa apprenant, traduzida por aprendente, para designar aluno e professor substituiremos por orientador.

As palavras aluno (aquele que não sabe nada) e professor (aquele que sabe tudo) criam barreiras na aprendizagem de uma língua. 0 orientador deve deixar de ensinar, mas sim, orientar o aprendente para que este descubra 0 conhecimento. É muito importante que o aluno descubra por si as regras gramaticais e do funcionamento da língua, afastando, assim, a importância do orientador. Essa atitude reduz o mito segundo o qual o professor é a peça fundamental para aprendizagem e que o aluno só pode conseguir dominar a língua caso conheça as regras gramaticais (cf. BURGEILE; SILVA; MELO, 2009).

Alguns pedagogos defendem a autonomia e a responsabilização do aluno pela sua aprendizagem. O abandono à dependência do orientador, a diversificação das atividades na aula e o uso de documentos autênticos encaminham para uma educação livre de crenças e preconceitos da didática tradicional. Entendemos que o orientador deve levar o aprendente à descoberta do saber. E o aprendente deve ser o ator principal no cenário ensinoaprendizagem. Por outro lado, o aprendente tem vários estilos de aprendizagem.

\section{Estilos de aprendizagem}


Aprender uma língua (seja materna, segunda ou estrangeira) envolve um conjunto amplo de conhecimentos e áreas que partem desde a cultura, a psicologia, a pedagogia, a sociologia entre outras. Essa diversidade faz com que o aprendente tenha estilos de aprendizagem. Lembrando que a aprendizagem deve ser centrada no aprendente. 0 estilo de aprendizagem, segundo Legendre (1993), é o modo preferencial modificável por meio do qual o sujeito gosta de apreender um conteúdo, resolver um problema, pensar ou simplesmente reagir a uma situação pedagógica. 0 estilo de aprendizagem seria a forma como 0 aprendente gosta de aprender. Isso varia de aprendente para aprendente da experiência adquirida e motivada no seio social e familiar. A escola costuma errar quando não leva em conta as necessidades dos aprendentes. Para Kolb (1984), o estilo de aprendizagem pode ser:

(a) Acomodador: quando o aprendente tende a aprender baseando-se mais em reflexões dos outros do que a partir de sua própria análise. 0 aprendente aprende jogando ou mesmo fazendo a dramatização com os colegas na aula. É um estilo em que o aprendente é mais participativo em trabalhos em grupo, ou seja, prefere trabalhos em grupo. Consideramos o tipo de aprendizagem mais ideal no ensino de línguas, pois ninguém aprende uma língua falando sozinho. Está se falando da abordagem comunicativa em que se aprende a língua comunicando (MARTINEZ, 2009). A efetivação da necessidade comunicativa se completa quando tem um receptor que por sua vez interage.

(b) Observador: o aprendente gosta de aprender a partir de novas experiências preferindo trabalhar sozinho e refletindo bastante. Os exercícios escritos individuais são os preferidos por este tipo de aluno. Geralmente é mais reservado, que interage pouco na aula. Esse tipo de aprendente tem conseguido sucesso em trabalhos individuais que, muitas vezes, remetem à expressão e à comunicação escrita. $\mathrm{O}$ orientador precisa prestar mais atenção neste aprendente fazendo sempre perguntas para perceber se está entendendo ou não. Tem comportamento contrário ao aprendente acomodador, pois precisa de atenção do orientador para confirmar a compreensão e a evolução da expressão e da comunicação oral. 
(c) Convergente: o aluno prefere aprender colocando em prática toda a sua conquista. É um aluno criativo e resolve os problemas de aprendizagem tomando decisões. Os aprendentes convergentes procuram relacionar o aprendizado com a realidade real. Alguns aspetos culturais que aparecem nas línguas diferem de cultura para cultura. A tarefa do orientador é de guiar o aprendente para que não caia em más interpretações fora do objetivo da aula. Um exemplo mais prático é a importância do gato na cultura moçambicana e francesa: em Moçambique o gato serve para caçar ratos e não para estimação. Os cuidados que os franceses têm com relação ao gato são diferentes. Pode ser estranho para um aluno moçambicano: dar banho, perfumar, levar ao veterinário, dormir com o animal na cama, passear com o animal na rua, etc.

Outro exemplo: um aprendente brasileiro pode enfrentar problemas para entender as palavras mairie (administração municipal) e préfecture (conjunto dos serviços do prefeito; local onde os serviços estão instalados). Na França, os serviços notariais funcionam na prefeitura, por exemplo, o que difere do contexto brasileiro. Estes aspetos culturais e particulares precisam ser bem explicados ao aprendente para que não generalize o conceito, pois a língua é uma prática social e há sempre relações entre língua, cultura e sociedade (HANKS, 2008). Vejamos agora como o linguista Armstrong pensa sobre os estilos de aprendizagem. Segundo Armstrong (1987), os estilos de aprendizagem podem ser:

(a) Estilo linguístico: no qual o aprendente tende a conversar na aula, respondendo as perguntas, contando histórias e falando sobre as experiências pessoais. É um aprendente mais extrovertido que se assemelha ao acomodador apresentado por Kolb (1984).

(b) Estilo musical: aquele aprendente que prefere adquirir conhecimentos da língua por meio de canto e/ou da música. A partir de canções ou músicas, realizam-se atividades diversas. O orientador que traz na aula uma música em francês pode estimular este tipo de aprendente despertando interesse, motivação. Da letra se pode explorar aspetos da 
gramática e do enriquecimento do léxico. Pode-se desenvolver atividades de expressão e de compreensão oral.

(c) Estilo espacial: o aprendente tem necessidade de meios visuais para a orientar atividades de aprendizagem. Este grupo de aprendentes prefere ilustrações, imagens de todo tipo: fixas ou móveis. A nossa pesquisa interessa bastante a este tipo de aprendente, pois as imagens são importantes para chamar atenção e na exploração de muitos aspetos da língua, tal como veremos mais adiante.

(d) Estilo intrapessoal: segundo Armstrong (1987), este tipo de aprendente prefere se concentrar exclusivamente no manual apresentado pelo professor e não cria ligação com outros documentos autênticos disponíveis. É um aprendente pouco motivado e precisa de atenção especial do orientador.

(e) Estilo interpessoal: prefere realizar atividades em grupo, responde positivamente as atividades de leitura, simulações e/ou dramatizações. É pouco criativo e precisa de uma orientação atenciosa do orientador.

Em síntese, pode-se dizer que não existe um estilo único de aprendizagem do aluno. Tanto Kolb (1984) quanto Armstrong (1987) não dão uma receita mágica para um sucesso do ensino de uma língua estrangeira. Uma turma é composta por várias culturas, várias experiências da vida que fazem com que o orientador não adote um só método. Por isso, o professor precisa diversificar as atividades na sala de aulas para satisfazer as necessidades dos aprendentes e alcançar os objetivos.

Não existe uma única metodologia que atende a todos os aprendentes. Cada um é particular e o professor precisa estar atento a essas particularidades. Por isso, o professor precisa diversificar as atividades nas aulas para satisfazer as necessidades dos aprendentes com objetivo de atingir os objetivos. Não existe uma única metodologia que atende a todos os aprendentes. Cada aprendente é particular, e o professor precisa estar atento a essas particularidades. Por isso, a escolha dos materiais a usar na sala deve ter em conta os estilos acima apresentados. Mas afinal quais são os materiais (documentos) que podem ser trazidos na aula ou pelos menos devem aparecer 
nos livros escolares? Vejamos como os linguistas tratam o conceito documento autêntico.

\section{Documentos autênticos: seus tipos}

Ao pensarmos nos tipos de aprendizagem dos aprendentes, precisamos pensar quais os materiais que interessam aos aprendentes? Quanto mais autênticos forem esses documentos, maior impacto darão aos alunos, na maioria dos casos, pois aprende-se para se usar no contexto real do dia a dia. O conceito documento autêntico surgiu na abordagem comunicativa como contraponto às metodologias anteriormente propostas pela metodologia oral, metodologia audiovisual e metodologia estrutural-global audiovisual (MARTINEZ, 2009). Vejamos como os vários linguistas definem esses materiais.

\section{Conceito de documentos autênticos}

Galisson e Coste (1976) definem documentos autênticos como todo material escrito ou audiovisual que não foi concebido para ser usado na aula de língua. Mas também há quem defina o documento autêntico como aquele material que não foi fabricado para fins pedagógicos (cf. DEBYSER, 2003). Entendemos por documento autêntico todo material escrito, visual, audiovisual e multimídia que não foi concebido para ensino e que é usada na sala sem que haja modificação do objetivo para o qual foi concebido. O documento autêntico faz entrar na sala informações, realidades, os objetos e situações do discurso existentes na cultura estrangeira chegando a testemunhar a realidade dessa cultura (ZARATE, 1986; DEBYSER, 2003).

Todas essas propostas convergem pelo fato de que os autênticos são materiais que não foram elaborados para o uso na aula de línguas, mas que o professor os traz para o fim pedagógico. É importante sublinhar que a partir do momento em que o orientador adapta o documento para o uso pedagógico, este perde a autenticidade, mas não perde os valores pelos quais foi elaborado. 
Consideramos um aspeto importante porque estes documentos serão encontrados pelo aprendente na comunicação real do dia a dia. Os materiais fabricados camuflam a variação e se inclinam aos objetivos da norma-padrão. A fala cotidiana é diferente daquela que é exigida pela gramática prescritiva e é muito importante que o aprendente domine todas as formas (padrão e nãopadrão).

Da perspectiva de uma pedagogia culturalmente sensível aos saberes dos alunos, podemos dizer que, diante da realização de uma regra não-padrão pelo aluno, a estratégia da professora deve incluir dois componentes: a identificação da diferença e a conscientização da diferença (BORTONI-RICARDO, 2004, p.42, grifos da autora).

Quanto às imagens, é importante que se traga materiais retirados dos jornais, revistas e outros materiais que são da convivência do cotidiano do aprendente, pois são essas realidades que o aluno encontrará.

\section{Tipos de documentos}

a) Documentos orais: são documentos orais as gravações de conversas, falas e outras situações de fala entre pessoas ou grupo de pessoas. 0 importante é que essas gravações devem ser feitas de forma espontânea, muitas vezes, sem que os falantes saibam que estão sendo gravados. Isso é importante porque mantém a fidelidade da fala não monitorada. $O$ material pode ser gravado e conservado em cassetes, CD, DVD, HD ou outros materiais disponíveis.

b) Documentos escritos: são documentos escritos (impressos ou digitais) que correspondem aos jornais (artigos, anúncios, publicidades, avisos, etc.), revistas, livros, cartas, recados, poemas, receitas de cozinha, formulários, boletins meteorológicos, internet que podem ser usados em sala de aula como autênticos, desde que não sejam previamente preparados para usos pedagógicos. Com esses documentos, o orientador pode preparar atividades que visam desenvolver as quatro competências comunicativas. 
c) Documentos icônicos: correspondem a imagens fixas. Entram, neste grupo, as fotografias, os desenhos, as gravuras, as pinturas entre outros que podem servir de matéria para discussão na aula de língua.

d) Documentos audiovisuais: correspondem às imagens móveis, ou seja, aquelas que pertencem à televisão. $O$ orientador pode planejar atividades com emissões televisivas ou outras filmagens que refletem a realidade sociolinguística. Pode-se fazer recortes de telenovelas, filmes, documentários, telejornais, reportagens, videoclipes de músicas entre outros materiais.

Para terminar, vale ressaltar que o uso de documentos autênticos na aula de línguas aproxima o aprendente à cultura da língua alvo. É importante frisar que a língua está intimamente ligada à cultura e o

papel da educação escolar e os desafios que teremos de enfrentar para promover processos educativos verdadeiramente informados pela perspectiva intercultural promovem, simultaneamente, a integração da sociedade numa perspectiva mais justa e consciente. (PESSOA, 2009, p.169).

\section{Imagem fixa: Fotografia}

Um livro didático sem imagens pode-se tornar cansativo, duro e desmotivador para parte dos alunos. As imagens, além de trazer o conteúdo do estudo da língua, trazem beleza, visualidade e motivação ao leitor/usuário. Não é por acaso que é impossível encontrar um manual didático sem imagens. Sabe-se também que há vários tipos de imagens: as fixas e móveis.

\section{Imagem fixa}

A imagem fixa é a mais antiga e surgiu com a humanidade. Segundo Fischer (2009), o homo sapiens sapiens utilizou a pictografia para fazer surgir a atual ortografia. A imagem fixa pode ser encontrada nas cavernas, em pedras, em árvores e em outras superfícies duras disponíveis na época. Segundo o autor 
Os hieróglifos individuais eram tirados ou elaborados do inventário da arte egípcia tradicional. Essa tendência de emprestar somente a ideia e/ou funções restritas da escrita, ao expressar a própria língua por meio de signos nativos repetiu-se ao longo da história. (FISCHER, 2009, p.30).

A imagem pode se apresentar em: desenho, pintura, desenho em quadrinhos, etc. Em todo canto, em todos os lugares deparamo-nos com a presença de imagens fixas que servem para mostrar uma determinada cultura, uma determinada situação ou mesmo publicidade. O aprendente está intimamente ligado à imagem fixa e é importante que esta comunicação prossiga em sala de aulas. A imagem fixa pode ser desenhada ou obtida de recursos tecnológicos, como é o caso da máquina fotográfica.

\section{Imagem móvel}

A imagem móvel é muito recente. Surgiu em 1923 com o cientista Vladimir Zworykin. A sua expansão pelo mundo ocorreu de forma rápida, dependendo do desenvolvimento econômico de cada país. A imagem móvel evoluiu desde o sinal analógico para sistema digital.

Hoje em dia, a maior parte dos habitantes de Moçambique, principalmente nas zonas suburbanas e urbanas têm pelo menos um televisor. A imagem móvel invadiu as casas, os lugares públicos (rodoviárias, hospitais, terminais, aeroportos), os meios de transportes (carros, ônibus, metrôs, aviões), em aparelhos tais como telefones, smathphones, tablets, etc. Por que não trazer a imagem às salas de aula?

É nesta visão que a imagem móvel é um potencial aliado ao ensino de uma língua estrangeira em salas de aula. Muitos aspetos socioculturais ficam mais claros e atrativos quando se usa a imagem móvel, que dizer, vídeo. Os vídeos podem mostrar a realidade cultural bem como a ligação com o ambiente concreto.

\section{Metodologia e análise}


Para a pesquisa, realizou-se observação em seis escolas secundárias sendo três públicas e as restantes privadas, todas localizadas na cidade de Maputo. O objetivo da observação das aulas era de verificar como os professores tratavam as imagens nas aulas de francês. Por motivo de ética em pesquisa, não identificaremos os nomes das escolas. Apenas codificaremos da seguinte forma: Escola privada 1, 2 e 3; Escola pública 1, 2 e 3. Em cada escola, observamos dois professores o que totaliza doze professores. Todos os professores são moçambicanos e fizeram a sua graduação (licenciatura) na Universidade Pedagógica de Maputo. Não interessa para a pesquisa a divisão dos professores por gênero.

A observação foi feita com base no preenchimento de uma grelha de observação composta por quinze questões. Por semana, os aprendentes têm 180 minutos sendo duas aulas de 45 minutos por dia e cada turma tem em média sessenta aprendentes. A organização da sala é tradicional (carteiras posicionadas para a lousa). Analisando estas condições, pode-se dizer que o número de alunos não permite que o professor tenha uma interação individual com os aprendentes. A disposição das carteiras não permite interação entre os aprendentes. Cada professor precisa ter pelo menos oito turmas para completar a carga horária semanal.

\section{O manual Le nouvel espaces-1}

É um manual escolhido pelo Ministério da Educação de Moçambique para servir de base ao ensino do francês nas $11^{\mathrm{a}}$ e $12^{\mathrm{a}}$ classes. $O$ manual foi produzido em Paris, França e é destinado ao ensino de Francês Língua Estrangeira (FLE). O Le nouvel espaces-1 traz inovações no domínio de aprendizagem e aquisição baseadas na clareza e rigor na progressão do aluno.

Composto por doze unidades (aqui designado por dossieurs), compreende um livro do aprendente, um caderno de exercícios, um guia pedagógico, três cassetes áudio e um videocassete acompanhado de um livro- 
guia de exploração e descoberta da civilização francesa através de imagens, reportagens e entrevistas. Os conteúdos estão programados para que o aprendente seja capaz de resolver provas do exame que permitem obter 0 Diploma de Estudos de Língua Francesa (DELF), avaliação reconhecida pelo Quadro Comum Europeu de Referência para as Línguas (Cadre Européen Commun de Référence pour les langues).

Como vimos anteriormente, o trabalho versa sobre a imagem fixa. Fizemos uma análise de todas as imagens presentes no manual, com atenção especial à fotografia. Da pesquisa identificou-se 294 imagens fixas dos quais dividimos em fotografias, desenhos e histórias em quadrinhos. Para discussão observemos o Gráfico 1.

Gráfico 1: As imagens fixas no livro "Le nouvel espaces-1"

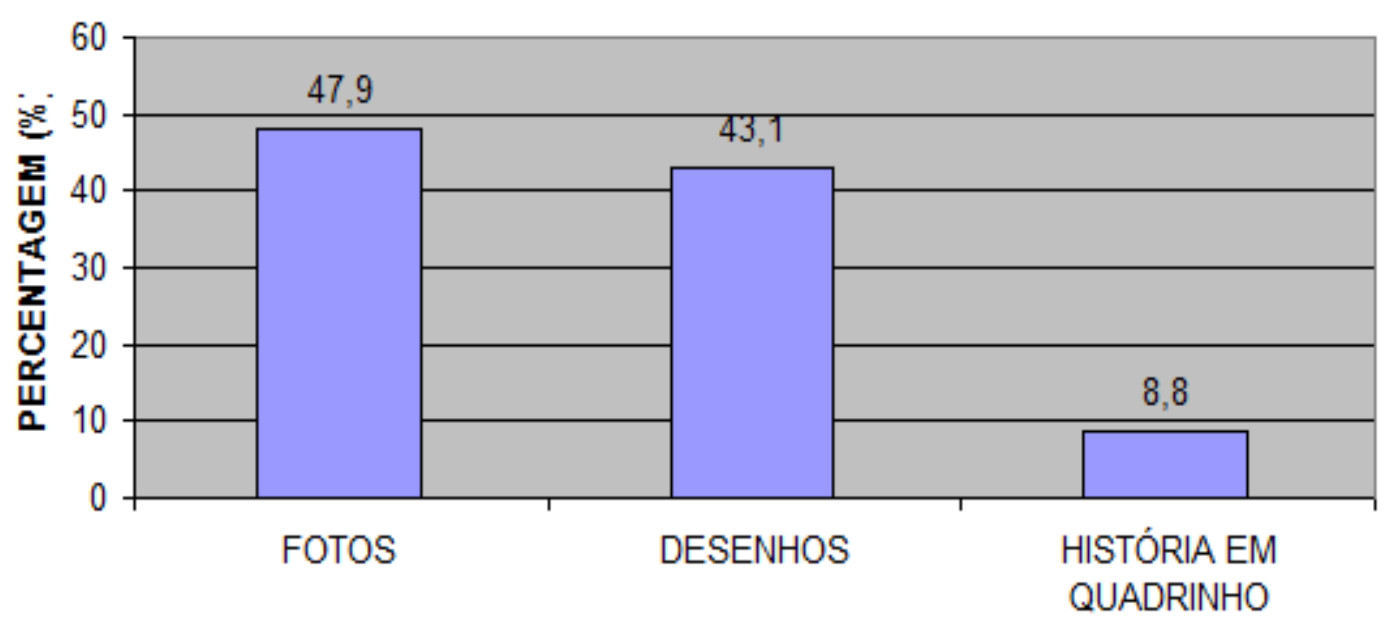

IMAGENS FIXAS

Fonte: Elaboração própria

Ao analisarmos o gráfico, percebe-se que a imagem tem um espaço privilegiado no manual em estudo. Como se pode constatar, há 141 fotografias, dado importante que atende ao interesse desta pesquisa pela fotografia. A fotografia sempre vem ao de cima, que antes da leitura do texto, a nossa imagem mental faz a leitura da imagem. Uma imagem mal colocada pode deturpar a compreensão da mensagem escrita. 
Os dados mostram que a fotografia é a mais destacada com $47,9 \%$ e faz parte da vida da sociedade em que vivemos, pois chama sempre a atenção. Por que não aproveitar condignamente este material para ensinar as línguas estrangeiras? Se pretendemos mostrar a civilização francesa podemos recorrer a fotografia mostrando e comentando os principais monumentos, a gastronomia, a arte, a dança entre muitos outros assuntos.

Segundo Muller (2009), a fotografia como suporte didático favorece a criatividade dos alunos e contribui para a resolução de problemas. Além disso, a fotografia permite interação entre os aprendentes, a troca de conhecimentos bem como a prática de expressão e compreensão oral. Ao mesmo tempo, podese partir do oral para o escrito, como por exemplo, a escrita da legenda, a escrita de cartas ou outro tipo de redação, despertando assim a expressão e comunicação escrita. Segundo Muller, "[...] na turma de língua, a criatividade permite realizar atividades que se aproximam a situações de comunicação cotidianas e úteis" (MULLER, 2009, p.92, nossa tradução). ${ }^{2}$

Esse aspecto é bem defendido pela abordagem comunicativa, pois o aprendente deve aprender a língua para melhor se comunicar na vida cotidiana. Não adianta ensinar a gramática prescritiva, ensinar exclusivamente as formas linguísticas da norma-padrão, pois essa norma não será usada na vida prática porque "a escola é, por excelência, o lócus - ou espaço - em que os educandos vão adquirir, de forma sistemática, recursos comunicativos que lhes permitam desempenhar-se competentemente em práticas sociais especializadas" BORTONI-RICARDO, 2009, p.75, grifo da autora).

É preciso sempre ter em conta as "necessidades dos aprendentes" (/es besoins des apprenants). Um aprendente que pretenda viajar e morar na França por algum tempo precisa de conhecimentos básicos em língua francesa que Ihes permitam realizar atividades essenciais, do tipo tomar o ônibus, ler as placas de sinalização, entender as direções, fazer pedidos de comida no restaurante, etc.

${ }^{2}$ En classe de langue, la créativité permet de réaliser des activités s'éloignant des situations de communication quotidiennes et utiles. 


\section{Problemas de ligação texto e imagem exigem muita atenção do orientador}

Um dos grandes problemas no tratamento das imagens fixas é a interpretação. A interpretação de uma imagem está intimamente ligada a cultura de uma determinada comunidade linguística. Uma simples imagem pode ter várias interpretações. Vejamos a foto 1 . Segundo Capelle e Gidon (1995), a foto vem dar um suporte à atividade proposta. Os autores propõem neste exercício, uma dramatização com a seguinte orientação: "você é vendedor (ou vendedora). Pergunte ao seu comprador o seu nome, seu endereço, seu código, seu andar, se existe um zelador no prédio, se existe elevador. (ver foto 1 , tradução nossa).

Foto 1: Atividade com fotografia

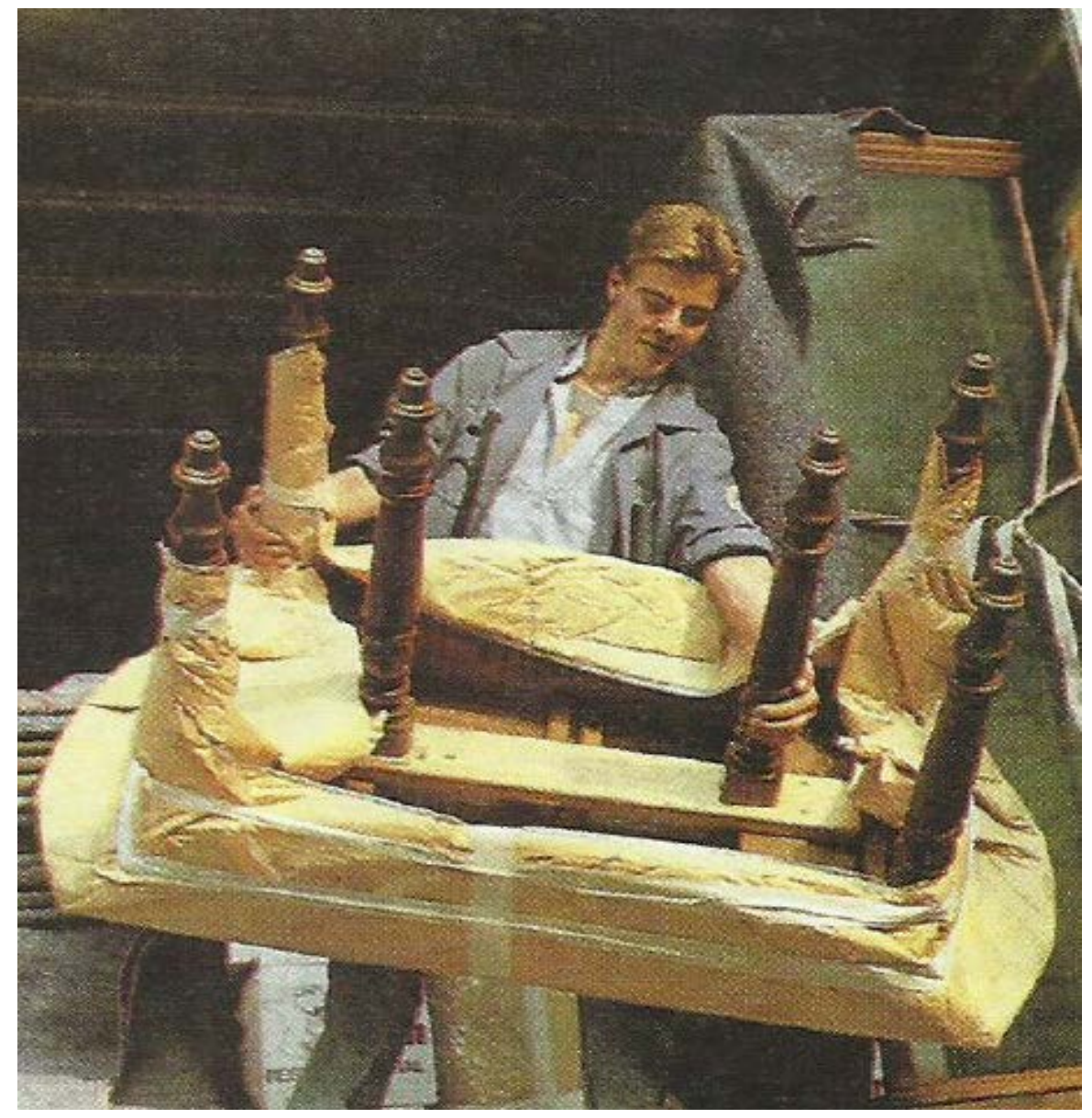

Fonte: Le nouvel espaces-1 (1995, p.47) 
Esta atividade pode ser complexa para os iniciantes. Senão vejamos:

a) A fotografia não tem nada a ver com a atividade;

b) Se a atividade é fazer perguntas sobre as compras, por que a foto simplesmente mostra alguém carregando uma mesa?

c) Como se pode partir de uma foto que mostra alguém carregando uma mesa para se chegar aos objetivos (provavelmente fazer perguntas para um comprador)?

d) $O$ ângulo da foto não permite ver os restantes objetos ainda embrulhados. Como se pode descrever assim?

Estas e muitas outras palavras podem aparecer na cabeça do aluno de forma sistemática e precisam ser respondidas porque até são pertinentes. A escolha da foto limita a criatividade do aluno e a possibilidade de desenvolver atividades de expressão. $\mathrm{O}$ que significa que a foto depende exclusivamente da criatividade do professor para trazer subsídios que podem animar os alunos. Antes de quaisquer atividades com a fotografia seria importante que 0 aprendente descrevesse a imagem para que este possa adquirir e enriquecer 0 seu vocabulário. Só assim é que se pode passar as atividades mais profundas. Uma simples descrição da imagem sem que haja objetivos previamente planejados não vale nada. É necessário que as atividades vão ao encontro da sequência dos conteúdos organizados pelo orientador.

\section{Resultado das observações}

Das observações realizadas nas seis escolas, constatou-se que os alunos se dispunham na mesma posição durante os dias em que se observou. Não havia mudanças (organização da turma em "U") ou em círculos nem houve formação de grupos. Todos os professores trabalham com fotos disponíveis no manual Le nouvel espaces-1 somente para se fazer uma simples descrição da imagem. Um aspecto negativo a relatar é que nem todos alunos tinham o livro colorido e recorriam as fotocópias para poder acompanhar as aulas. Uma foto 
em preto e branco é menos proveitosa do que a foto em cores. Das seis turmas observadas, $65 \%$ utilizaram uma foto ligada ao texto sendo todas das escolas privadas.

Nas escolas públicas, observou-se que os alunos pouco participaram espontaneamente, ou seja, os aprendentes esperavam que o professor indicasse alguém para responder. As observações trouxeram algumas desvantagens, uma vez que a presença do pesquisador provocou alteração do comportamento dos aprendentes, segundo o professor. Os alunos mais inteligentes procuraram responder todas as perguntas para preencher a fraca participação dos restantes elementos da turma.

Em cerca de $85 \%$ dos alunos observados em turmas de francês nas escolas descritas percebe-se a desmotivação dos alunos quanto se trata de fotos. Uma vez que os alunos nunca foram à França, deveriam ser essas fotos que aproximariam o aluno da realidade da cultura francesa. A ideia seria essa só que a realidade terrena se mostrou contrária. Entendemos que a existência de condições para a projeção da foto provavelmente traria uma interação mais adequada, pois todos os alunos ficariam atentos na grande tela de projeção. 0 número reduzido de carteiras não permite conforto dos alunos, o que pode trazer má disposição, desmotivação e desatenção em dias em que faz muito calor. São problemas que podem ser resolvidos com apoio em infraestruturas nas escolas moçambicanas.

\section{0 tratamento da fotografia}

A fotografia, por ser um material indispensável na aprendizagem de línguas estrangeiras, há um conjunto de atividades principais que podem ser desenvolvidas para despertar interesse pela língua, para a divulgação da cultura da língua alvo, para desenvolver várias atividades pedagógicas como por exemplo:

Descrever a foto e enriquecer o vocabulário ou léxico da língua; inventar (imaginar) uma história partindo da ideia principal representada na foto; criar 
atividades que permitem a elaboração de um curto texto ou mesmo legenda, atividade que estimula a expressão escrita; fotocopiar a foto e fazer com que os aprendentes descubram as cores originais; mostrar uma foto aos aprendentes e pedir para dizer quais os objetos que faltam; os aprendentes podem elaborar perguntas para fazer às personagens presentes na foto; explicar as relações de parentesco numa foto com elementos de uma família; escrever legenda numa série de fotos apresentadas; elaboração de uma carta, um recado, uma publicidade, partindo de uma foto.

Elaboração de um plano de atividades indicando os dias de semana partindo de uma foto; conhecer a civilização francesa tais como: Musée de Louvre, Tour Eiffeil, Notre Dame de Paris, Le Palais omnisports de Paris-Bercy, La grande biblioteque de France, entre outros monumentos importantes. Estas e muitas outras atividades podem ser desenvolvidas na aula de francês, desde que o orientador se permita variar as atividades. Como se pode ver, a pesquisa não traz uma "varinha mágica" para o sucesso do ensino com o uso da foto. Apenas traz algumas sugestões que possam ser aplicadas para a melhoria da qualidade de ensino do francês. A recomendação mais importante é que o orientador deve conhecer os estilos de aprendizagem dos seus alunos. Ao conhecer, poderá preparar exercícios que motivem e ativem a aprendizagem dos aprendentes.

A foto está presente nas nossas vidas. Cidadãos do mundo desenvolvido ou em vias de ser desenvolvido, quase todos são fotógrafos. Por quê? Porque a maioria dos telefones já possui a função máquina fotográfica e as pessoas procuram registrar momentos especiais ou não das suas vidas. Essas fotos podem chegar à sala de aula para servir de material de aprendizagem da língua francesa. Poderia ser interessante pedir aos aprendentes que trouxessem fotos do dia a dia, e essas fotos seriam projetadas através de um projetor de eslaides. Essa projeção possibilitaria uma visualização mais ampla. Da análise, pode-se explorar diferentes aspetos comunicativos, desde a gramática até ao do léxico. 


\section{Considerações finais}

A fotografia é um material didático importante no ensino de línguas estrangeiras. Cabe ao orientador escolher a fotografia autêntica que pode ser recortada no jornal, da revista ou de muitos outros materiais. A pesquisa coloca o aprendente no centro das atividades, e o orientador aparece com um papel secundário. Toda aprendizagem deve ser centrada no aprendente. O professor (que designamos por orientador) simplesmente passa a ser como um treinador de futebol, pois não chega a entrar em campo para jogar. O ensino de línguas estrangeiras deve favorecer o conhecimento prévio do aprendente, valorizando e encorajando os progressos.

É muito importante responsabilizar o aprendente pela sua própria aprendizagem devendo, por vezes, pedir para que traga material que achar conveniente para ser utilizado na aula. Esta atitude pode motivar o aprendente pelo fato de ser parte ativa do processo de ensino e aprendizagem. A maior desvantagem desta metodologia se verifica quando o orientador/professor está pouco preparado. Se assim for, estará limitado, encontrará dificuldades para ajudar ao aprendente na interpretação e discussão do material trazido.

O manual Le nouvel espace-1 é um instrumento importante, mas deve ser acompanhado de outros documentos autênticos. O objetivo dessa atitude é de procurar atender às necessidades dos aprendentes. O professor não é o único detentor do saber, por isso, a autonomia do aluno deve ser valorizada, fato que não se verificou nas escolas públicas de Maputo. 0 número excessivo de alunos por turma e a falta de materiais prejudicam de certa forma os trabalhos dos professores de francês em Moçambique, fato que pode ser ultrapassado pela formação contínua de professores e a formação de turma com pelo menos 20 a 25 alunos. As escolas privadas, pelo contrário, fornecem o manual ao aluno, fato que faz com que o aprendente trabalhe fora da sala de aula. 
Retomando as hipóteses iniciais, notou-se que o trabalho com a foto não tem sido valorizado em sala de aula nas seis escolas pesquisadas. Os professores observados se limitam apenas na foto disponível no livro e não procuram outros recursos que possam animar mais os alunos e despertar estilos de aprendizagem. Contrariamente às hipóteses, a pesquisa mostrou que a foto ajuda e serve de meio de aprendizagem no ensino de Francês, pois a foto é algo mais próximo aos alunos do ensino médio.

Quase todos alunos têm o Facebook, que é um serviço de redes sociais, que usa bastante os recursos fotográficos em geral. No Facebook, os alunos trocam informações e ideias. Já que os alunos estão familiarizados com fotos, este material poderia ser mais útil no ensino da língua francesa. A última hipótese ficou confirmada, pois os professores do ensino médio conhecem a metodologia do trabalho com a foto só que não têm tempo; as turmas numerosas, de fato, dificultam um trabalho mais individualizado.

Nesta pesquisa, procuramos discutir metodologia de ensino do francês com o uso da foto; analisamos o manual escolar Le nouvel espace-1 que é o manual usado nas escolas do ensino médio em Moçambique. Vimos as suas fraquezas e pontos fortes. No ensino de línguas, a presença do professor parece indispensável uma vez que é ele que pesquisa e procura metodologias para facilitar a aprendizagem do aluno. É necessário que esteja de lado um professor competente e ativo para despertar interesse e motivação no aluno. Nesta pesquisa, procuramos propor algumas formas possíveis que podem melhorar a qualidade da aula de francês, uma vez que ela é importante para a comunicação com o mundo francófono e o acesso ao conhecimento (Bibliografia em língua francesa).

\section{Referências}

ARMSTRONG, Thomas. In their own way. Los Angels: Jeremy P.Tarcher inc., 1987. 
BORTONI-RICARDO, Stella Maris. Educação em língua materna: A sociolinguística na sala de aula. São Paulo: Parábola, 2004.

BURGEILE, Odete; SILVA, Daianne Severo da.; MELO, Michele Nascimento. As implicações das crenças do professor para o ensino-aprendizagem de línguas estrangeiras. In: BURGEILE, Odete.; BARRETO ROCHA, Júlio César. (Org.). Estudos em linguística aplicada: multiculturalismo e ensino-aprendizagem de línguas. São Carlos: Pedro e João Editores/Porto Velho: EDUFRO, 2009.

CAPELLE, Guy; GIDON, Noelle. Le nouvel espaces-1. Paris, Hachette, 1995. CHAMPY, Philippe; ETEVE, Christiane. Dictionnaire encyclopédique de l'éducation la formation. Paris: Nathan, 1994.

DEBYSER, Francis. La découverte du parlé grâce au document sonore. In Français Dans le Monde, №145. Paris: Hachette, 2003.

FISCHER, Steven Roger. História da escrita. (trad. Mirna Pinsky). São Paulo: Ed. UNESP, 2009.

GALISSON, Robert; COSTE, David. Dicionário de didática das línguas. Coimbra: Livraria Almedina, 1983.

GOMES, Maria Lúcia de Castro. Metodologia do ensino de língua portuguesa. 2ed. Curitiba: IBPEX, 2011.

GUIRRUGO, Orlando. 0 ensino bilíngue em Moçambique: um desafio políticoestratégico. Folha de linguística e literatura. № 4. Maputo, outubro 2009. pp.19-25.

HANKS, William F. Língua como prática social: das relações entre lingual, sociedade e sociedade a partir de Bourdieu e Bakhtin. São Paulo: Cortez, 2008.

KOLB, David. Experimental learning : experience as the source of learning and development. Torono: Prentince Hall, 1984.

LEGENDRE, Renald. Dictionnaire actuel de l'éducation. Paris : Eska/Guérin, 1993.

MARTINEZ, Pierre. Didática de línguas estrangeiras. Trad. Marcos Marcionilo. São Paulo: Parábola, 2009.

MINISTÉRIO DA EDUCAÇÃO. Plano curricular do ensino secundário geral: documento orientador, objectivos, política, estrutura, plano de estudos e estratégias de implementação. Maputo: MINED /INDE, 2007. 
MINISTÉRIO DA EDUCAÇÃO. Programas de francês do $2^{\circ}$ ciclo do ensino secundário geral. Maputo: MINED, 1994.

MULLER, Catherine. La créativité dans des commentaires de photographies en classe de français langue étrangère. In: Synergies Europe. N04, Paris, 2009. pp.89-104.

NGUNGA, Armindo; BAVO, Nazia. Uso e práticas linguísticas em Moçambique: avaliação da vitalidade linguística em seis distritos. Maputo: UEM, 2011.

PESSOA, Maria do Socorro. Pesquisas sociolinguísticas e ensino de línguas. In: BURGEILE, Odete; BARRETO ROCHA, Júlio César. (Org.). Estudos em linguística aplicada: multiculturalismo e ensino-aprendizagem de línguas. São Carlos: EDUFRO, 2009.

REPÚBLICA DE MOÇAMBIQUE. Constituição da República. Maputo: Imprensa Nacional, 2004.

REY, Alain. Le Robert micro: dictionnaire d'apprentissage de langue française. Paris: Dictionnaires le Robert, 1998.

TIMBANE, Alexandre António. A variação e a mudança lexical da língua portuguesa em Moçambique. Tese. (Doutorado em Linguística). Faculdade de Ciências e Letras, Departamento de Linguística e Língua Portuguesa, Araraquara, 2013.

ZARATE, Geneviève. Enseigner une culture étrangère. Paris: Hachette, 1986. 